\title{
Evaluation of the Human Discomfort Caused by Ship Vibrations
}

\author{
Laurentiu Picu \\ Dunarea de Jos" University, Galati, Romania \\ Eugen Rusu \\ "Dunarea de Jos" University, Galati, Romania, eugen.rusu@ugal.ro
}

Follow this and additional works at: https://jmstt.ntou.edu.tw/journal

Part of the Fresh Water Studies Commons, Marine Biology Commons, Ocean Engineering Commons, Oceanography Commons, and the Other Oceanography and Atmospheric Sciences and Meteorology Commons

\section{Recommended Citation}

Picu, Laurentiu and Rusu, Eugen (2021) "Evaluation of the Human Discomfort Caused by Ship Vibrations," Journal of Marine Science and Technology. Vol. 29: Iss. 1, Article 5.

DOI: $10.51400 / 2709-6998.1004$

Available at: https://jmstt.ntou.edu.tw/journal/vol29/iss1/5

This Research Article is brought to you for free and open access by Journal of Marine Science and Technology. It has been accepted for inclusion in Journal of Marine Science and Technology by an authorized editor of Journal of Marine Science and Technology. 


\title{
RESEARCH ARTICLE \\ Evaluation of the Human Discomfort Caused by Ship Vibrations
}

\author{
Laurentiu Picu, Eugen Rusu* \\ "Dunarea de Jos" University, Galati, Romania
}

\begin{abstract}
The present work analyzes the subjective responses of people exposed to transient vibrations caused by systems with a single degree of freedom. In this context, the main objective of the research was to identify the main effect of vibrations on people's well-being at work (in particular on vessels crew) and to discover those frequencies that lead to the greatest discomfort. In order to achieve this goal, 12 laboratory experiments were carried out involving ten male subjects in good health, aged between 28 and 42 . The variables of the vibratory system considered are: acceleration $\left(4.8 \div 8.6 \mathrm{~m} / \mathrm{s}^{-2}\right)$, amplitude $(1 \div 3.7 \mathrm{~mm})$, frequency $(4 \div 10 \mathrm{~Hz})$ and exposure time (10 and $30 \mathrm{~min})$. At the end of the experiments, it was found that half of the subjects abandoned the experiment in case number 3 from Table $2\left(\right.$ for $a=7.6 \mathrm{~m} / \mathrm{s}^{-2}, \mathrm{f}=7.8 \mathrm{~Hz}$ and exposure time $=10 \mathrm{~min}$ ). The responses of the participants in the experiment were analyzed by means of two different methods: the Likert scale and the Semmes-Weinstein monofilament method. As a result, it was found that, as the vibration parameters rise, the subjects' discomfort increases. Interestingly, this growth does not appear to be a linear one, but a "power" type one. It was also found that there were no significant differences between the subjects' responses, although naturally, every person reacts in his own way to different stressors.
\end{abstract}

Keywords: Stressors, Transient vibrations, Discomfort, Likert scale, Semmes-Weinstein method

\section{Introduction}

$\mathrm{N}$ avigation has been a means of travelling and obtaining food even from ancient times. Archaeological discoveries showed that humans used this form of transport as early as 40,000 to 45,000 years ago. The transport of goods plays today an extremely important part in the economy. Water transportation includes a wide range of ships, from small boats on rivers up to marine cargoes that can carry hundreds of thousands of tons of freight. In this context, the health condition of the operating ship crew is of crucial importance. Consequently, identifying accurately the factors responsible for human discomfort on board should take priority, since such discomfort can induce serious health problems [1].

"A ship that is floating on water will always have a motion, even if the engine is stopped. The reasons for this are: ocean currents, wind, tide, etc. When the ship is moving through water under propulsion various motions can be observed. Mainly rolling \& pitching can be felt by the personnel onboard" [2] (Fig. 1).

There are six kinds of ship motions: „1. Rolling: is the rotary movement of the ship around the $\mathrm{X}$-axis. 2. Surging: is the linear movement of the ship along the $X$-axis. 3. Pitching: is the rotary movement of the ship around the Y-axis. 4. Swaying: is the linear movement of the ship along the $Y$-axis. 5. Yawing: is the rotary movement around the Z-axis. 6 . Heaving: is the linear movement of the ship $t$ along the $\mathrm{Z}$ axis." [3]. 


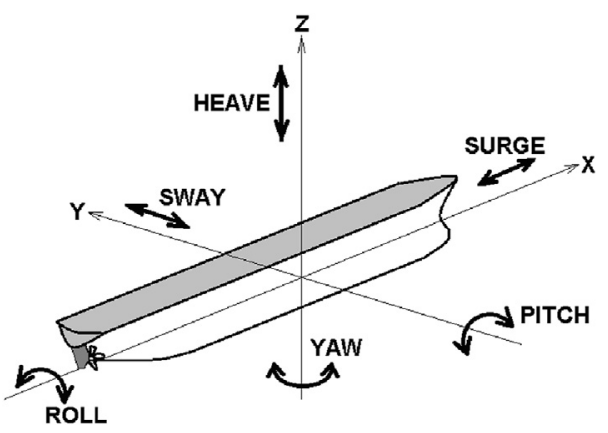

Fig. 1. Vessel motions in 6 degrees of freedom [2].

Obviously, all these types of movements have a negative impact on the physical and mental capacities of the people on board. In addition to physiological problems (increased cardiac and respiratory rhythm, high blood pressure, vasoconstriction, endocrine secretions, impaired central nervous system, and circadian rhythm), there are issues affecting comfort and performance (pain, nausea, vision problems, posture, movement and coordination decline, and perceptions altered) [4] (see Fig. 2).

The circadian rhythm influences a person's normal biological behaviors. Circadian Rhythm Sleep Disorders (CRSDs) occur when external factors disturb the natural rhythm of sleep [6]. There

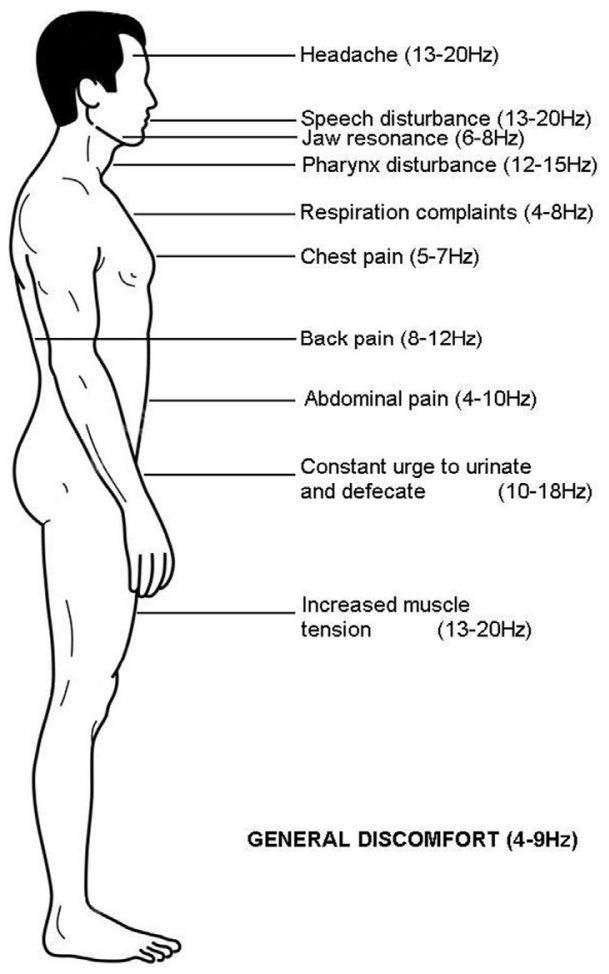

Fig. 2. Complaints in various organ regions in relation to vibration frequencies [5]. are several types of CRSDs. Of interest in this instance, are those related to shift-work and jet-lag, both caused by an "inability to adapt to a forced or voluntary change in sleep" [6].

Changing sleep patterns due to work requirements is increasingly common. Thus, there are people who work a 24-h shift. When these people lie down, they describe sleep as "irreparable or unsatisfactory" [7].

In cases where the working staff in question is made up of seafarers, circadian rhythm disorders are a frequent occurrence. This is directly correlated with the blood pressure values. Blood pressure is one of the most important cardiovascular risk factors, responsible for $13 \%$ of the known causes of death worldwide.

Normal blood pressure should be between 90 and 120 for systolic pressure and between 60 and 80 for diastolic pressure. Blood pressure fluctuates throughout the day, depending on the effort sustained and has a daily pattern or patterns. It begins to increase a few hours before we wake up and continues to rise during the day [8].

High blood pressure has various causes: unbalanced diet, alcohol consumption, smoking, exposure to stress, alternating shift work, etc., all of which are part of the seafarers' lifestyle. Added to these factors is living and working in an environment where there is vibration [9].

Also, another important factor is marching time. If for river ships this time is of the order of $0.5 \div 2$ months, the seagoing personnel may sail on the ships for up to 6 months or even more.

Therefore, human discomfort induced by exposure to transient ship vibrations from the single degree of freedom systems becomes a subject which worth to be examined.

\section{Materials and methods}

The study involved 10 sailors staying on a plate mounted on a vibratory system (Fig. 3 ). This was a preliminary study conducted on a limited number of individuals, which means that it was only a case study. While it is true that we cannot generalize from the results presented herewith, we still can draw several significant conclusions. Furthermore, river ships, like the one targeted in this paper, generally have a small number of crew members. That is why it would be difficult to perform studies on a larger number of sailors operating on the same boat. On the other hand, each boat has some particular characteristics, as well as its navigation route. From this perspective, each particular case can be considered fairly relevant, as it describes a 


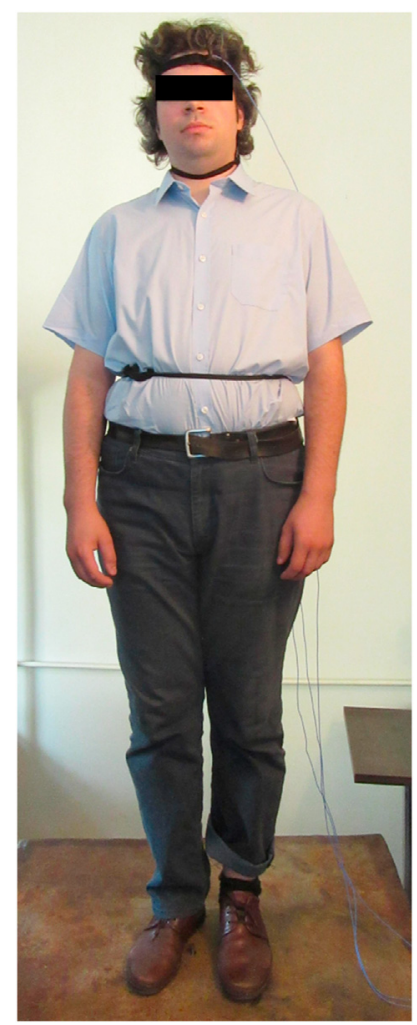

Fig. 3. Subject on the vibratory system with accelerometers layout.

real-life situation. Furthermore, similar studies that complement this one have also been performed, see for example the results of some other works carried out by the authors of this article [10-12]. For the purpose of this study, only two oscillatory movements (roll and pitch) to which navigators are subjected during navigation were simulated. The reason why we chose these movements was because of the vibrating system limitations.

"Transient vibration is defined as a temporarily sustained vibration of a mechanical system. It may consist of forced or free vibrations, or both" [13].
Table 2. Experimental parameters.

\begin{tabular}{llllll}
\hline Case & Exp & $\mathrm{A}(\mathrm{mm})$ & $\mathrm{a}(\mathrm{m} / \mathrm{s} 2)$ & $\mathrm{f}(\mathrm{Hz})$ & $\mathrm{t}(\mathrm{min})$ \\
\hline 1 & 1 & 1 & 4.3 & 4 & 30 \\
& 2 & & 4.8 & 6.5 & 30 \\
& 3 & & 5.2 & 7.8 & 30 \\
2 & 4 & 1.6 & 6.4 & 6.5 & 30 \\
& 5 & & 6.8 & 7.8 & 10 \\
& 6 & & 6.9 & 10 & 10 \\
3 & 7 & 3.3 & 7.2 & 6.5 & 10 \\
& 8 & & 7.6 & 7.8 & 10 \\
& 9 & & 8.1 & 10 & 10 \\
4 & 10 & 3.7 & 8.5 & 6.5 & 10 \\
& 11 & & 8.6 & 7.8 & 10 \\
& 12 & & 8.8 & 10 & 10 \\
\hline
\end{tabular}

Ten male subjects took part in this experiment. They were aged between 28 and 42, and were all in good health (Table 1). The participants were informed of what the experiment consists of, but they were also told that they could leave the experiment without giving any explanation. The subjects unanimously agreed to participate in the experiments.

All subjects have work experience (5-22 years); 4 of them smoke; 4 of them drink more than $200 \mathrm{~mL}$ of alcohol/day. In addition, 4 of them have cardiovascular diseases in the family and many of them have family problems.

The responses of the subjects were analyzed for the cases where the vibratory system transmits amplitudes: $1 \mathrm{~mm} ; 1.6 \mathrm{~mm} ; 3.3 \mathrm{~mm}$ and $3.7 \mathrm{~mm}$ at frequencies of $4 \mathrm{~Hz}, 6.5 \mathrm{~Hz}, 7.8 \mathrm{~Hz}$, and $10 \mathrm{~Hz}$. These amplitudes were selected, in relation to the previous measurements made directly on the ship and showing similarity to real cases. As for the frequencies, they were chosen because most human organs have natural frequencies within this range: $\in(4 \div 10) \mathrm{Hz}$. Both amplitudes and frequencies were modified using a vibration generator.

The experimental parameters considered are shown in Table 2.

Table 1. The anthropometric data of test subjects.

\begin{tabular}{|c|c|c|c|c|c|c|c|c|}
\hline Subject & Age (years) & Weight (kg) & Height $(\mathrm{m})$ & Smoker & Drinker $^{a}$ & $\begin{array}{l}\text { Work experience } \\
\text { (years) }\end{array}$ & $\begin{array}{l}\text { Cardiovascular diseases } \\
\text { in the family }\end{array}$ & $\begin{array}{l}\text { Family } \\
\text { problems }\end{array}$ \\
\hline S 1 & 35 & 90 & 1,79 & - & - & 15 & - & $x$ \\
\hline S 2 & 37 & 81 & 1,80 & - & - & 17 & - & $x$ \\
\hline S 3 & 38 & 95 & 1,82 & $X$ & $X$ & 16 & $X$ & $X$ \\
\hline S 4 & 31 & 92 & 1,75 & - & - & 12 & $X$ & - \\
\hline S 5 & 29 & 100 & 1,98 & $X$ & - & 5 & - & $x$ \\
\hline S 6 & 40 & 70 & 1,65 & $X$ & $X$ & 22 & $X$ & $X$ \\
\hline S 7 & 42 & 80 & 1,82 & - & - & 19 & - & - \\
\hline S 8 & 28 & 95 & 1,74 & - & - & 9 & $X$ & - \\
\hline S 9 & 29 & 85 & 1,81 & - & $X$ & 10 & - & $x$ \\
\hline S 10 & 39 & 106 & 1,88 & $X$ & $X$ & 21 & - & - \\
\hline
\end{tabular}

${ }^{\text {a }}$ More than $200 \mathrm{~mL}$ of alcohol/day, not on board of the ship. 
Table 3. Symptoms caused by exposure to various frequency ranges from $1 \div 20 \mathrm{~Hz}$.

\begin{tabular}{ll}
\hline Symptoms & Frequency $(\mathrm{Hz})$ \\
\hline General discomfort & $4-9$ \\
Headaches & $13-20$ \\
Jaw resonance & $6-8$ \\
Speech disturbance & $13-20$ \\
Respiration complaints & $12-16$ \\
Chest pain & $5-7$ \\
Abdominal pain & $4-10$ \\
Urinary problems & $10-18$ \\
Increased muscle tension & $13-20$ \\
Heaviness of movement & $4-8$ \\
Muscle contraction & $4-9$ \\
\hline
\end{tabular}

These values were chosen to replicate the ship's movements as realistically as possible (Table 3 ). It is also known that low values of oscillation frequencies are the most harmful to the human body. ISO 2631 compiles these data into a set of vibration criteria curves for longitudinal and transverse vibrations in the frequency range $1 \div 80 \mathrm{~Hz}$.

The accelerations transmitted to the crew were measured with Piezotronics 356A16 PCB triaxial accelerometers placed on the lumbar and cervical regions and on the forehead, respectively (Fig. 3), connected to the $01 \mathrm{~dB}-$ Metravib NetdB12 acquisition unit, as well as a triaxial accelerometer installed inside a SEAT-PAD, placed under the foot and connected to a Maestro vibrometer. The results were processed with the dBFA software. The exposure times were $10 \mathrm{~min}$ and $30 \mathrm{~min}$, respectively.

The experiments were consecutive. All the subjects gave their written agreement to participate in this experiment. At the same time, the subjects were informed that they could leave the experiment whenever they felt they were unable to continue.

After exposure, the subjects were asked to complete the degree of discomfort [14] on the Likert scale (Table 4) and then were tested with ,the Semmes-Weinstein monofilament method: a monofilament nylon wire exerts a $10 \mathrm{~g}$ force when pushed against the skin for $1 \mathrm{~s}$. Patients who cannot feel this pressure on the surface of their legs are considered to have lost their tactile perception. The tests were repeated three times" [16].

Table 4. Likert scale [15].

\begin{tabular}{lc}
\hline Degree of discomfort & Scale \\
\hline Very high & $4 \div 5$ \\
High & $3 \div 4$ \\
Slightly & $2 \div 3$ \\
Low & $1 \div 2$ \\
None & $0 \div 1$ \\
\hline
\end{tabular}

Table 5. Definitions of hypertension grade and classification of blood pressure [17].

\begin{tabular}{llll}
\hline Category & $\begin{array}{l}\text { Systolic } \\
(\mathrm{mmHg})\end{array}$ & $\begin{array}{l}\text { Diastolic } \\
(\mathrm{mmHg})\end{array}$ \\
\hline Optimal & $<120$ & and & $<80$ \\
Normal & $120-129$ & and/or & $80-84$ \\
High normal & $130-139$ & and/or & $85-89$ \\
Grade 1 hypertension & $140-159$ & and/or & $90-99$ \\
Grade 2 hypertension & $160-179$ & and/or & $100-109$ \\
Grade 3 hypertension & $\geq 180$ & and/or & $\geq 110$ \\
Isolated systolic hypertension & $\leq 140$ & and & $<90$ \\
\hline
\end{tabular}

In addition, in order to study how vibrations influence the physiological state of the subjects, blood pressure (systolic and diastolic) was measured for each subject immediately after the experiment (whether abandoned or completed). Blood pressure varies depending on several parameters: age, sex, BMI, lifestyle, medical history, etc. Normally, these values should be within the following ranges (Table 5):

The blood pressure was measured using a wrist blood pressure monitor (Fig. 4).

\section{Results}

In the first part of the study, 4 cases of experiments were performed; subjects were exposed to 12 types of vibration with different accelerations (a), amplitudes (A), frequencies $(v)$ and exposure time (t) (Fig. $5 \div 8$ ). It can be seen that the parameters of the vibrating system were chosen in such a way that when the exposure time is long, the amplitude and frequency are low (Figs. 5 and 6) and when the exposure time is short, the amplitude and frequency are high (Figs. 7 and 8). Furthermore, these parameters have been chosen so as not to put excessive strain on the subjects.

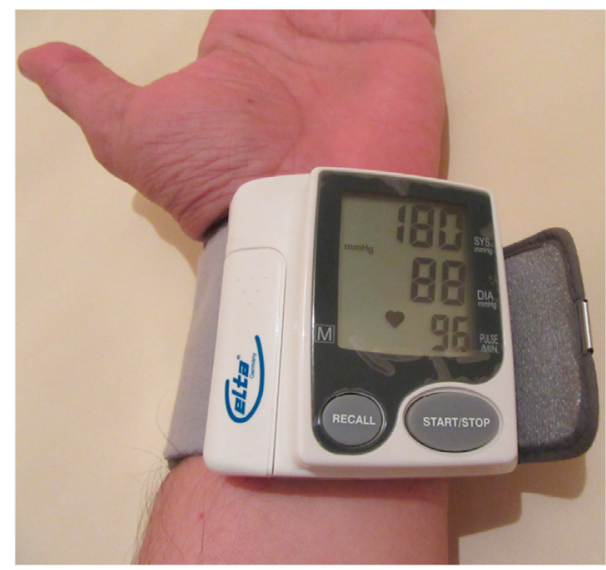

Fig. 4. Wrist blood pressure monitor. 


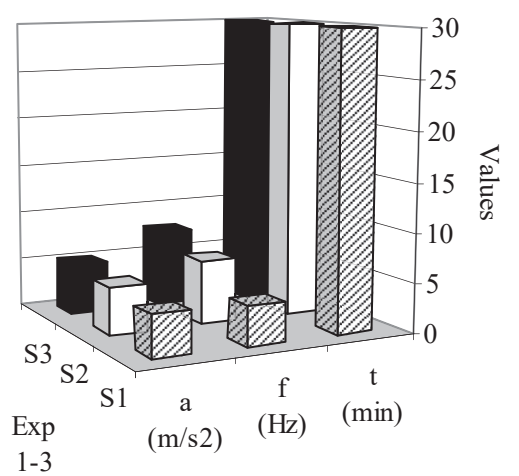

Fig. 5. Averaged acceleration at the forehead level for Case 1 $(A=1 \mathrm{~mm}): S 1=\operatorname{Exp} 1(/ / /), S 2=\operatorname{Exp} 2$ (ㅁ), S3 = $\operatorname{Exp} 3(\mathbf{\square})$.

Thus, at the forehead level, for $\mathrm{A}=1 \mathrm{~mm}$, the accelerations are in the range $4.3 \div 5.2 \mathrm{~m} / \mathrm{s}^{-2}$, for $\mathrm{A}=1.6 \mathrm{~mm}$, in the range $6.4 \div 6.9 \mathrm{~m} / \mathrm{s}^{-2}$, for $\mathrm{A}=3.3 \mathrm{~mm}$, in the range $7.2 \div 8.1 \mathrm{~m} / \mathrm{s}^{-2}$ and for $\mathrm{A}=3.6 \mathrm{~mm}$, the accelerations are in the range $8.5 \div 8.8 \mathrm{~m} / \mathrm{s}^{-2}$.

The bar charts presented above show that the exposure time does not significantly influence the magnitude of the accelerations transmitted through the body of the subjects. The data confirm once again that the accelerations depend on frequency and amplitude, so while for $\mathrm{A}=1 \mathrm{~mm}$ and $\mathrm{f}=4 \div 7.8 \mathrm{~Hz}$, the acceleration does not vary so much, for $\mathrm{A}>3 \mathrm{~mm}$ and $\mathrm{f}>6 \mathrm{~Hz}$, the accelerations are higher than $7 \mathrm{~m} / \mathrm{s}^{-2}$, which is extremely burdensome for the human body.

Accelerometers installed under the foot and placed on the lumbar, cervical and forehead measured the accelerations transmitted to the human body. Not surprisingly, it was observed in each case that the further the body region is from the source of vibrations, the smaller acceleration level is registered. This is clearly due to the gradual

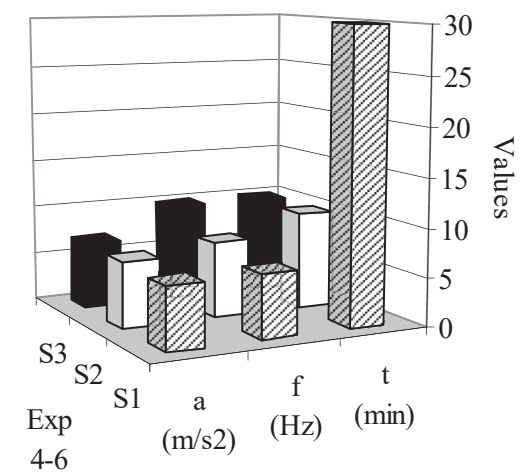

Fig. 6. Averaged acceleration at the forehead level for Case 2. $(A=1.6 m m): S 1=\operatorname{Exp} 4(/ / /), S 2=\operatorname{Exp} 5($ (口), S3 = $\operatorname{Exp} 6(\boldsymbol{\square})$. attenuation of vibrations through the human body (Fig. 9).

Fig. 9 illustrates that the attenuation of the accelerations through the human body is quite high for this frequency band. This attenuation is a "power" function:

$$
\begin{aligned}
& \text { Case1: } \mathrm{a}=\mathrm{f}\left(\frac{1}{\Pi^{0.2654}}\right) \\
& \text { Case2: } \mathrm{a}=\mathrm{f}\left(\frac{1}{\Pi^{0.2647}}\right)
\end{aligned}
$$

Case3 $: a=f\left(\frac{1}{\Pi^{0.3525}}\right)$

Case $4: a=f\left(\frac{1}{\Pi^{0.3534}}\right)$

where $\bar{a}$ is the average value of accelerations and $\Pi$ is the place where the accelerometer was fastened. From Eqs. (1)-(4) it can be observed that for cases 1 and 2, the attenuation is higher (the exponent is 0.26) than in cases 3 and 4 (where the exponent is 0.35). This proves that an attenuation of the acceleration through the human body was achieved depending not only on the frequency, but also on the specific area where the measurement was made. Even though the number of subjects considered is small, these findings can be a starting point for future research.

\section{Discussions}

The discomfort of the subjects who participated in these experiments was studied in the second part of the study:

a) the subjects answered the Likert test (Table 6):

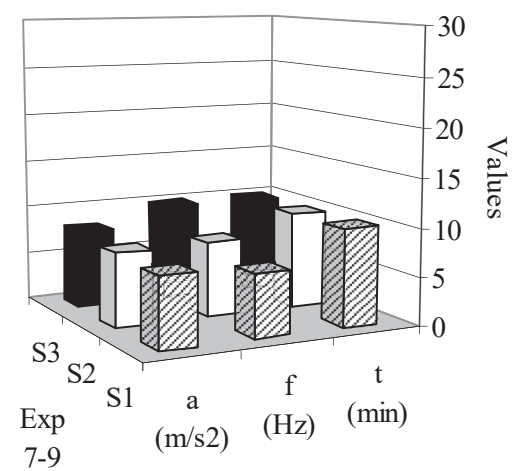

Fig. 7. Averaged acceleration at the forehead level for Case 3. $(A=3.3 \mathrm{~mm}): S 1=\operatorname{Exp} 7(/ / /), S 2=\operatorname{Exp} 8$ (ם), S3=Exp $9(\square)$. 


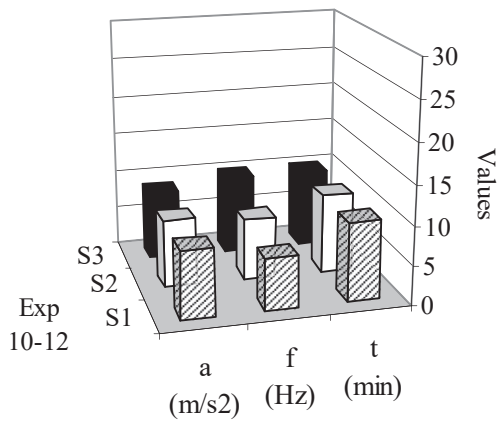

Fig. 8. Averaged acceleration at the forehead level for Case 4. $(A=3.7 \mathrm{~mm}): S 1=\operatorname{Exp} 10(/ / /), S 2=\operatorname{Exp} 11(\mathrm{a}), S 3=\operatorname{Exp} 12$

Table 6 shows different responses to this type of stressor, although all subjects are in good health conditions. Considering Body Mass Index (BMI) categories: BMI under 18.5 means underweight, normal weight for $\mathrm{BMI}=18.5 \div 24.9$, overweight if $\mathrm{BMI}=25 \div 29.9$ and obesity for BMI over 30 , this group of subjects have 3 obese and 5 overweight.

- Of the 10 subjects, only 2 did not drop out, participating in the experiment until the end: subjects 2 and 7 . They are 37 and 42 years old, respectively, and have a BMI of 24.69, and BMI of 24.15, respectively, (both normal weight) and stated they do not drink, nor smoke, have long work experience and did not have cardiovascular diseases registered in their families.

- The first to quit the experiment was subject no. 5 . Furthermore, of the 12 sets of determinations, he managed to withstand only 7 . At the frequency of $7.8 \mathrm{~Hz}$ and acceleration of $7.6 \mathrm{~m} / \mathrm{s}^{-2}$ he desisted. This subject is 29 years old, has a BMI of 25.51, so he is overweight, he smokes and does not have wide work experience.

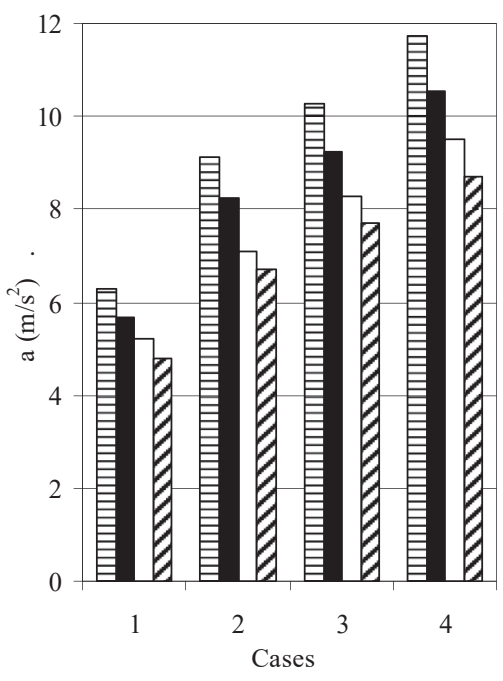

Fig. 9. Transmitted average accelerations measured at each level. (三) Under the foot; ( $\mathbf{\square})$ - Lumbar; () - Cervical; (///) - Forehead.

- Subject no. 9 was the second to give up. Of the 12 sets of determinations, he managed to withstand only 8 . At the frequency of $10 \mathrm{~Hz}$ and acceleration of $7.6 \mathrm{~m} / \mathrm{s}^{-2}$ he desisted. This subject is 29 years old, has a BMI 25.95, so he is overweight, does not have long work experience, does not smoke, but drinks more than $200 \mathrm{~mL}$ of alcohol/ day (not on board of the ship).

- The third who gave up the experiment was subject no. 8. Of the 12 sets of determinations, he managed to withstand only 9 . He gave up the last set. This subject is 28 years, has a BMI of 31.38 (moderate grade I obesity), does not have long work experience, does not smoke, does not drink but has cardiovascular diseases in the family.

Table 6. Likert test responses for each subject.

\begin{tabular}{|c|c|c|c|c|c|c|c|c|c|c|c|c|c|}
\hline \multirow[t]{2}{*}{ Case } & \multirow{2}{*}{$\begin{array}{l}\text { A } \\
(\mathrm{mm})\end{array}$} & \multirow{2}{*}{$\begin{array}{l}\mathrm{F} \\
(\mathrm{Hz})\end{array}$} & \multirow{2}{*}{$\begin{array}{l}\mathrm{T} \\
(\mathrm{min})\end{array}$} & \multicolumn{10}{|c|}{ Likert test response*/Subject } \\
\hline & & & & 1 & 2 & 3 & 4 & 5 & 6 & 7 & 8 & 9 & 10 \\
\hline 1 & 1 & 4 & 30 & 1 & 1 & 1 & 1 & 1 & 1 & 1 & 1 & 1 & 1 \\
\hline 2 & & 6.5 & 30 & 2,2 & 1 & 2,5 & 2,3 & 2,8 & 1,7 & 1 & 1,8 & 1,6 & 2,2 \\
\hline 3 & & 7.8 & 30 & 2,8 & 1,5 & 3,2 & 3,1 & 3,4 & 2,4 & 1,6 & 2,4 & 2,6 & 2,7 \\
\hline 4 & 1.6 & 6.5 & 30 & 3,4 & 2,2 & 3,5 & 3,7 & 4 & 3,3 & 2,4 & 2,8 & 3,4 & 3,4 \\
\hline 5 & & 7.8 & 10 & 3,7 & 2,8 & 3,7 & 3,8 & 4,5 & 3,5 & 3 & 3,4 & 3,8 & 3,8 \\
\hline 6 & & 10 & 10 & 4 & 3,4 & 3,8 & 4 & 5 & 3,8 & 3,5 & 4 & 4,5 & 4 \\
\hline 7 & 3.3 & 6.5 & 10 & 4,5 & 4 & 4,2 & 4,6 & 5 & 4,1 & 4 & 4,4 & 4,7 & 4,3 \\
\hline 8 & & 7.8 & 10 & 4,8 & 4,2 & 4,5 & 4,8 & & 4,6 & 4,4 & 4,8 & 5 & 4,7 \\
\hline 9 & & 10 & 10 & 5 & 4,3 & 4,8 & 5 & & 4,8 & 4,4 & 5 & & 5 \\
\hline 10 & 3.7 & 6.5 & 10 & 5 & 4,5 & 5 & 5 & & 5 & 4,5 & & & 5 \\
\hline 11 & & 7.8 & 10 & & 4,8 & 5 & & & 5 & 4,5 & & & \\
\hline 12 & & 10 & 10 & & 4,8 & & & & & 5 & & & \\
\hline
\end{tabular}


Fig. 10. Semmes-Weinstein monofilament.

- Next, subjects no. 1 (BMI $=28.09$ - overweight, non-drinker, non-smoker), no. 3 (BMI $=28.68$ overweight, drinker, smoker), no. 5 (BMI $=25.71$ - overweight, drinker, smoker) and no. 10 $(\mathrm{BMI}=29.99$ - overweight, non-drinker, nonsmoker), gave up one after the other.

Discomfort $=0.0072 \mathrm{x}^{3}-0.1396 \mathrm{x}^{2}+1.2681 \mathrm{x}-0.1357$ with $\mathrm{R}^{2}=0.9996$

where $\mathrm{x}=$ number of experiments performed.

b) The subjects were then tested with the SemmesWeinstein monofilament method.

The assessor sensors are portable; they have a standard deviation of $5 \%$ for each force and for each case. These sensors have a filament that bends when the maximum force threshold is reached (Fig. 10).

For the experiments there were used the heaviest filaments the subjects could sense before starting the tests. The test was repeated three times by applying monofilaments to all fingertips (subjects felt a maximum of $3 \times 10$ fingers $=30$ taps).

The results confirm what these people stated when asked to answer the Likert test. It has been noticed that the fingers of the subjects become increasing numb as the vibration parameters rise. In the last part of the experiments, the subjects could no longer respond to the test (Fig. 11).

Fig. 11 shows the number of taps felt per subject for each experimental case (Table 6). As can be seen, only 2 subjects completed all the sets of experiments (S2 and S7); the rest gave up - most of them at Case no. $4\left(\mathrm{a}=8.6 \mathrm{~m} / \mathrm{s}^{-2}\right)$. This is clearly noticeable from the large number of marks on the graphic at the beginning of the experiments and the extremely small number at the end of them.

For this reason, only 2 curves that best fit the experimental results were represented graphically:

For subject $\mathrm{S} 2(-): \mathrm{N}=-10.626 \cdot \ln (\mathrm{C})+36.782$ with $\mathrm{R}^{2}=0.8073$

For subject S7(-): $\mathrm{N}=-12.03 \cdot \ln (\mathrm{C})+37.471$ with $\mathrm{R}^{2}=0.8274$

where $\mathrm{N}$ is the number of taps felt and $\mathrm{C}$ is the case number.

It was found that this decrease in the acceleration value (a) depends, as a power function, on the distance $(x)$ between the body area where the accelerometers are placed and the vibrating system. This function is:

$\mathrm{a}=\mathrm{k} \cdot \mathrm{x}^{-\mathrm{q}}$

where $\mathrm{k}$ and $\mathrm{q}$ are constants that depend on the vibration parameters. For example, in the cases

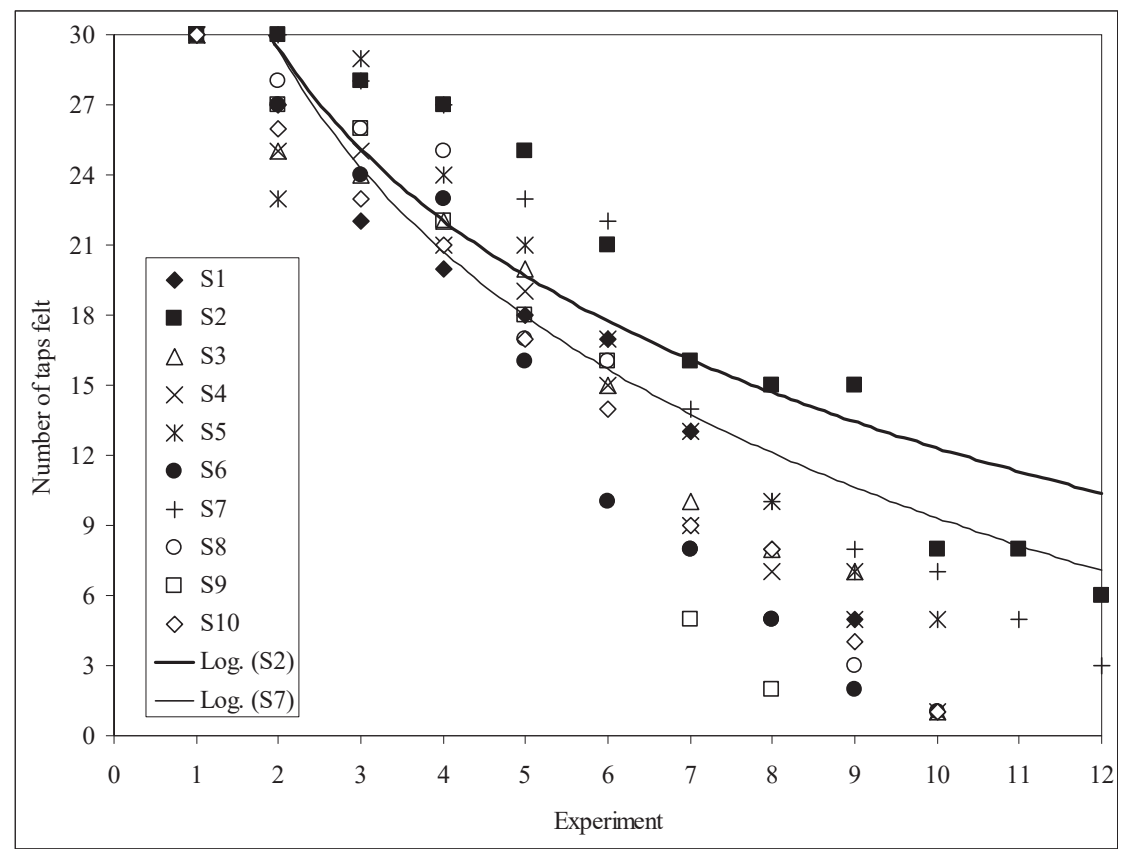

Fig. 11. Number of taps felt by each subject for each experiment. 


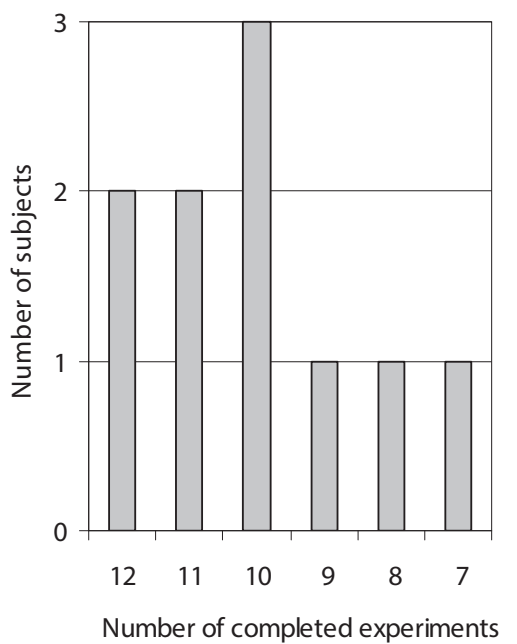

Fig. 12. Number of subjects who finished the experiments.

studied in this paper, the values for $\mathrm{q}$ are 0.26 for cases $1 \& 2$, and for cases $3 \& 4: 0.35$. In other words at low frequencies, the attenuation is higher than at high frequencies for this frequency band. It can be also seen that the amplitude A has no bearing on the magnitude of accelerations transmitted through the human body.

By analyzing the number of taps felt for subject 2 and for subject 7 (the only ones who completed all the experiments), the following logarithmic dependence was found:

$\mathrm{N}=\mathrm{a} \cdot \ln (\mathrm{C})+\mathrm{b}$

where $a$ and $b$ are constants that depend on the vibration parameters.

It was clearly seen that, because of the increase of the values of these parameters, the subjects had

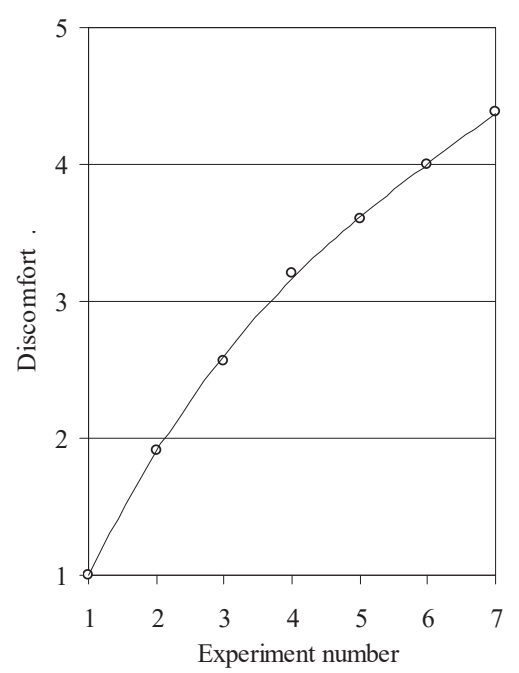

Fig. 13. Average Likert response.
Table 7. Blood pressure values by age.

\begin{tabular}{llll}
\hline Age & Minim & Normal & Maxim \\
\hline $25-29$ & $109 / 76$ & $121 / 80$ & $133 / 84$ \\
$30-34$ & $110 / 77$ & $122 / 81$ & $134 / 85$ \\
$35-39$ & $111 / 78$ & $123 / 82$ & $135 / 86$ \\
$40-44$ & $112 / 79$ & $125 / 83$ & $137 / 87$ \\
\hline
\end{tabular}

their fingers numbed and were unable to feel the monofilament.

Thus, we determined how vibrations are attenuated through the human body for certain parameters of the vibratory system (acceleration, frequency, amplitude and exposure time).

The second part of the paper analyzed the discomfort caused by these vibrations to the 10 subjects. Of these, only 2 completed the entire set of 12 experiments (Fig. 12).

It was found that there are 2 factors that most influence the resistance to this type of stressor: work experience and BMI. This does not mean that smoking and drinking are irrelevant, but their impact is negative, weakening the resistance.

After calculating an average only for the first 7 experiments (that involved all the subjects), it was found that the discomfort they declared is placed on a third-grade polynomial (Eq. (5)), its value increasing with the increase of vibration parameters values (Fig. 13).

Regarding the results obtained by the individuals subjected to the Semmes-Weinstein test, these already confirm the validity of the Likert evaluation responses.

After the vibration measurements and the psychological and sensorial tests, in the third part of the paper, the blood pressure (systolic and diastolic)

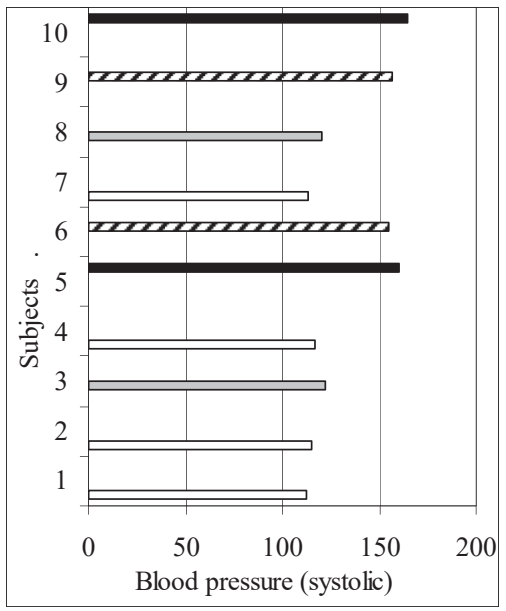

Fig. 14. Average blood pressure (systolic) variation for each subject ( $\square$ ) - Normal; (ם) - rehypertension, (//) - Hypertension stage 1; (ם) Hypertension stage 2. 


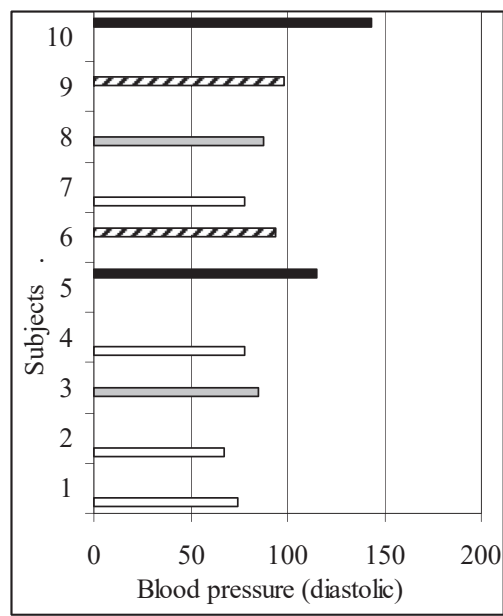

Fig. 15. Average blood pressure (diastolic) variation for each subject ( $\square$ ) - Normal; (ם) - Prehypertension, (//) - Hypertension stage 1; (ם) Hypertension stage 2.

was measured. Its abnormal values, not only cause discomfort, but can become also very dangerous.

For the subjects aged between of 28 and 42, the blood pressure must be within the limits indicated in Table 7:

Figs. 14 and 15 illustrate that overweight subjects, smokers, and those who drink more than $200 \mathrm{~mL}$ of alcohol/day have high blood pressure, falling under Stages 1 and 2 of hypertension. However, none of them experienced a fit of hypertension. All these subjects were also those who failed to complete the vibration tests, and the results from SemmesWeinstein and Likert tests were worse than those of the rest.

\section{Conclusions}

From these determinations, it can be concluded that, in addition to all the problems inherent in such a profession, the vibrations transmitted by the working equipment are an extremely important factor. Thus, of the 10 people subjected to different accelerations and exposure times, only 2 were able to complete the experiments; subject no. 5 gave up on experiment no. $8\left(\mathrm{a}=7.6 \mathrm{~m} / \mathrm{s}^{-2}, \mathrm{f}=7.8 \mathrm{~Hz}\right.$ and exposure time $10 \mathrm{~min})$. Subject no. 9 gave up on experiment no. $9\left(\mathrm{a}=8.1 \mathrm{~m} / \mathrm{s}^{-2}, \mathrm{f}=10 \mathrm{~Hz}\right.$ and $10 \mathrm{~min}$ exposure time). Subject no. 8 gave up on experiment no. $10\left(\mathrm{a}=8.5 \mathrm{~m} / \mathrm{s}^{-2}, \mathrm{f}=6.5 \mathrm{~Hz}\right.$ and $10 \mathrm{~min}$ exposure time). Then, one by one, the other five subjects gave up. This demonstrates that vibration acceleration is in the root cause of the discomfort experienced by the sailing crew.
In addition to the fact that Semmes-Weinstein and Likert tests confirm this, an extremely important factor for the physical and psychological health of the sailors is the value of the blood pressure. In sailors' case, it is normal for blood pressure during exercise to increase while they are active, but it should return to normal values after the working hours. Normally, the blood pressure is lower during sleep, if the sleeping periods are regular, according to a normal circadian rhythm. Of the 10 subjects, only 4 had normal blood pressure, the rest had prehypertension ( 2 subjects), hypertension stage 1 ( 2 subjects), and hypertension stage 2 (2 subjects).

In this paper, we were able to demonstrate by 3 methods: two subjective (the Likert scale and the Semmes-Weinstein monofilament testing) and one objective (blood pressure measurement), that the vibrations transmitted to humans induce a state of discomfort proportional to the parameters of the vibrating system, but also to the subjects' characteristics (Table 1), so implicitly, such vibrations can lead to work accidents.

Measured results show that it is imperative to reduce workload and stress in order to prevent certain tragedies.

\section{Acknowledgement}

This work was carried out in the framework of the project "Excellence, performance and competitiveness in the Research, Development and Innovation activities at "Dunarea de Jos" University of Galati", acronym "EXPERT", financed by the Romanian Ministry of Research and Innovation in the framework of Programme 1-Development of the national research and development system, Sub-programme 1.2-Institutional Performance - Projects for financing excellence in Research, Development and Innovation, Contract no. 14PFE/17.10.2018.

\section{References}

[1] Picu L. Biodynamics of the human body under hand-arm vibration: Development of a biomechanical model. In: Proceedings of 11th European Congress and Exposition on Noise Control Engineering, Hersonissos, Crete; 2018. p. $2663-8$.

[2] Prasanna D. The ship's motions at sea. HubPages, "Travel and places" Travel transportation. 2014.

[3] Subramaniam H. Ship stability-III. Nutshell Series Book, Vol. 6. India: Vijaya Publication; 2014.

[4] Picu L, Rusu EVC. Single degree of freedom vibrating system and the prediction of human discomfort due to its transient vibrations. In: Proceedings of 6th Scientific Conference of Doctoral Schools "Dunarea de Jos" University of Galati, Romania, Book of abstract 148; 2018. 
[5] Calhoun SR. Human factors in ship design: Preventing and reducing shipboard operator fatigue. University of Michigan, Department of Naval Architecture and Marine Engineering, U.S. Coast Guard Research Project; 2006.

[6] Barion A. Circadian rhythm sleep disorders. Dis Mon 2011; 57(Issue 8):423-37.

[7] Agarwal M, Sharma K, Jamal M. Shift work sleep disorder and complications. Sleep Dis Ther 2014;3:154.

[8] Egan CE, Espie BH, McGrann S, McKenna KM, Allen JA. Acute effects of vibration on peripheral blood flow in healthy subjects. Occup Environl Med 1996;53:663-9.

[9] Giurgiu DI, Bardac DI, Răulea CI. Studiu asupra prevalenţei hipertensiunii arteriale la personalul medical dintr-un spital clinic județean de urgență din România. Acta Medica Transilvanica 2011;2(3):87-93 (in Romanian, with English Abstract).

[10] Picu L, Picu M, Rusu EVC. An investigation into the health risks associated with the noise and vibrations on board of a boat - a case study on the danube river. J Mar Sci Eng (JMSE) 2019;7(8):1-15. 2019; Paper ID 258.

[11] Picu L, Picu M. An analysis of whole-body vibration and hand-arm vibration exposure on the Danube ship crew. IOP Conf Ser: J Phy: Conf Ser 2019;1297(1).

[12] Picu L, Rusu EVC. Multiple physical stress exposures of sailors on several ships - a longitudinal study. In: Annals of
"Dunarea de Jos" University, of Galati, Fascicle II-Mathematics, Physics, Theoretical Mechanics, ISSN 2067 - 2071, Year X(XLI) 2018. Vol. 1; 2018. p. 84-93.

[13] Ledezma-Ramirez DF, Ferguson NS, Brennan MJ. An overview of the single degree of freedom system and zener model for passive shock isolation. In: ISVR Technical Memorandum No 947; 2005.

[14] Picu L, Picu M, Rusu EVC. Evaluation of human exposure to whole-body vibration - verification method of Stevens's power law. In: Proceedings of 18th International Multidisciplinary Scientific GeoConference, Albena, Bulgaria; 2018.

[15] Likert R. In: Woodworth RS, editor. A technique for the measurement of attitudes. Ph.D. Thesis, Archives of Psychology; 1932.

[16] Picu M, Sireteanu T. The Semms-Weinstein monofilament examination and Purdue Pegboards test as a screening tool for peripheral neuropathy caused by vibrations. Proc Romanian Acad - ser A 2016;17(2):144-51. The Publishing House of the Romanian Academy.

[17] Williams B, Mancia G, Spiering W, Rosei EA, Azizi M, Burnier M, et al. 2018 ESC/ESH Guidelines for the management of arterial hypertension. European Heart J 2018, 39(33):3021-104. 